\title{
Modelling of paralytic shellfish toxin biotransformations in the course of Crassostrea gigas detoxification kinetics
}

\author{
Marielle Guéguen ${ }^{\mathrm{a}}$, Régis Baron ${ }^{\mathrm{b}, *}$, Michèle Bardouil ${ }^{\mathrm{c}}$, Philippe Truquet ${ }^{\mathrm{c}}$, Hansy Haberkorn ${ }^{\mathrm{d}}$, \\ Patrick Lassus ${ }^{c}$, Laurent Barillé ${ }^{\mathrm{e}}$, Zouher Amzil
}

\author{
a Microbiologie d'Intérêt Laitier et Alimentaire EA 3214, Université de Caen, Esplanade de la Paix, BP 5183, \\ 14032 Caen, France \\ b Ifremer, Laboratoire Science et Technologie de la Biomasse Marine, Rue de l'lle d'Yeu, BP 21105, 44311 \\ Nantes cedex, France

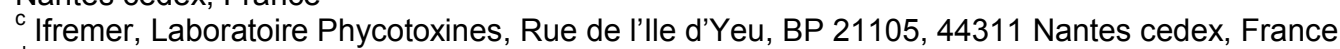 \\ d Laboratoire des Sciences de l'Environnement Marin, Institut Universitaire Européen de la Mer, Université de \\ Bretagne Occidentale, Place Copernic, Technopôle Brest-Iroise, 29280 Plouzané, France \\ e Molécule, Mer et Santé, Université de Nantes, 2 rue de la Houssinière, BP 92208, 44322 Nantes cedex 3 , \\ France
}

*: Corresponding author : Régis Baron, Tel.: +33 240374221 ; fax: +33 240374071.

email address : regis.baron@ifremer.fr

\begin{abstract}
:
The aim of this study was to evaluate the importance of biotransformation of paralytic shellfish toxins during the detoxification process in contaminated oysters. Mathematical models based upon the detoxification patterns of digestive gland and other tissues were developed. It was demonstrated that biotransformations do not seem to play an important role in digestive gland or other tissue detoxification kinetics with our data set. Moreover, different toxin transfers from digestive gland toward other tissues were investigated. No significant transfer was highlighted in our data set. These first conclusions were drawn after comparing the results obtained from 13 biotransformations and identifiable transfer scenarios. Finally, to determine a more robust model, all 12 states corresponding to toxic compounds and tissues were aggregated into a single state model. The best adjustment was obtained with a simple one-compartment model based on total flesh toxicity with elimination rate expressed by a function depending on initial concentrations of GTX3 and GTX2 (i.e. the two major toxic compounds found in contaminated oysters).
\end{abstract}

\section{Highlights}

Importance of toxic paralytic shellfish toxins biotransformation during detoxification process in contaminated oysters. Using mathematical models, biotransformations do not seem to play an important role. The best model obtained was an aggregated model with a simple one-compartment model based on two major compounds.

Keywords : Detoxification kinetics modelling ; Biotransformation of saxitoxin analogues ; Oyster 


\section{Introduction}

In recent decades, a global increase in microalgal blooms has been observed in marine coastal environments (Cordier et al. 2000). These blooms can produce discoloured waters worldwide, displaying a wide range of colours from deep brown to orange-red (Bricelj and Shumway 1998; Hallegraeff 1995). This phenomenon is due to high concentrations of microalgae, which can reach several million cells per litre. Microalgae are consumed by filterfeeders, particularly bivalves. Some of them are able to synthesise toxic secondary metabolites which are then released and later accumulated by primary consumers. Primary consumers can then become prey for secondary consumers and so on, allowing metabolites to accumulate in the various links of the food chain (Jaime et al. 2007; Jiang et al. 2006).

Bivalve molluscs are defined as motionless primary consumers which can filter large amounts of sea water per unit of time (Bricelj and Shumway 1998). Due to their low sensitivity to phycotoxins, they do not protect themselves against high contamination levels (Haberkorn et al. 2010). They are considered good vectors in terms of toxin transfer in the different links - including man - of the trophic web (Choi et al. 2006; Kvitek et al. 2008). As a precaution, specific safety thresholds have been established for each toxin by the European Economic Community directive $n^{\circ} 492 / 91$ (EEC 1991). When these thresholds are either reached or exceeded in shellfish meat, shellfish growing areas are closed with a ban on the bivalve mollusc market, causing both consumers and producers distrust as well as economic losses (Bricelj and Shumway 1998; Lassus et al. 2005). For instance, in New England in 2005, shellfish areas closures led to financial damage estimated at 23 millions dollars (Jin et al. 2008).

In France, the three types of toxins present along the coast are diarrheic, paralytic and amnesic shellfish toxins. Lipophilic toxins appeared in 1983 followed by paralytic shellfish toxins in 1988 (Ledoux et al. 1991; Masselin et al. 2000; Sechet et al. 2003). Amnesic shellfish toxins have only been detected on the French coasts for the last ten years (Amzil et al. 2001). These outbreaks do not only concern France, but also coastal areas all around the world (Bricelj and Shumway 1998; Van Egmond et al. 1993). On the other hand, neurotoxin and ciguatera are not present along mainland coasts, although ciguatera is frequently observed in the West Indies and French Polynesia. Paralytic toxins remain the most dangerous in the case of ingestion by man. The French shellfish industry is the 2nd largest producer in Europe behind Spain, with approximately 245,000 t in 2004 (FAO, 2009). This production is dominated by bivalve molluscs and notably Pacific oyster Crassostrea gigas $(105,250 \mathrm{t})$.

Economic losses due to the closure of shellfish production areas are a threat to the industry. It is therefore important to find some solutions to reduce drastically the duration of sales bans.

Mathematical models are sometimes used to forecast the detoxification kinetics of phycotoxin-contaminated bivalve molluscs. When available, they may be considered as efficient tools for the management of contaminated farming areas. On one hand, such models 
should help understand the biological mechanisms and environmental parameters likely to modify detoxification kinetics. On the other hand, they should predict the time needed for an efficient detoxification and provide the preliminary information required for the implementation of detoxification units. Currently, 'compartment-type' models are available. They are usually made of one or two 'black box' systems in which only the input and output are known (Blanco et al. 1999; Lassus et al. 2007; Silvert and Cembella 1995). These models generally give a good description of observed detoxification kinetics but they always need a new fit for any new data set. Taking into account mollusc physiology, toxin physico-chemical properties as well as intrinsic and extrinsic variables should enable a better prediction of detoxification kinetics. The present work focuses on the interaction between the physicochemical properties of Paralytic Shellfish Toxins (PST) and the modelling of Crassostrea gigas (Pacific oyster) detoxification kinetics.

Paralytic shellfish toxins are composed of 21 chemical compounds with close chemical structures, all derived from saxitoxin (Figure 1). These compounds are polar low molecular weight tetrahydropurines which are thermostable, stable in acidic medium and unstable in alkaline medium (likely to be oxidised). They are classified according to four main groups: carbamates (saxitoxin STX, gonyautoxins GTX2, GTX3, GTX1, GTX4, neosaxitoxin neoSTX), N-sulfocarbamoyls (B toxins like B1 or GTX5, B2 or GTX6 according to NorthAmerican or Japanese nomenclatures, C toxins: C1, C2, C3, C4), decarbamoyls (dcSTX, dcGTX2, dcGTX3, dcGTX1, dcGTX6 and dcNeo) and deoxycarbamoyl toxins (doSTX, doGTX2, doGTX3) which have a hydrogen atom in position R4 (Fig. 1).

Possible PST biotransformations are epimerisation, hydrolysis and reduction (Oshima 1995; Fig. 2). They are the result of specific physico-chemical conditions, and of the activities of either enzymes or bacteria naturally present in shellfish meat (Sato et al. 2000; Smith et al. 
2001). For instance, Placopecten magellanicus can convert gonyautoxins into saxitoxin or neosaxitoxin provided enzymes or certain bacteria are present (Sato et al. 2000).

Biotransformations are observed during either contamination or detoxification periods (Oshima 1995; Smith et al. 2001). PST relative toxicity must include all present analogues since each of them displays a different toxicity pattern when tested on mice by i.p. injection (Oshima 1995). The toxin content of mollusc meat is expressed as STX equivalents thanks to a conversion coefficient specific to each analogue (Oshima 1995). During detoxification, biotransformations into less toxic compounds will potentially accelerate the detoxification rate (following the hypothesis of specific elimination rates for identical compounds). In contrast, biotransformations giving more toxic compounds will potentially slow down detoxification rates. It thus seems necessary to take into account the relative evolution of each compound in the context of the present study.

Stomach and digestive gland (DG) are the preferred organs for biotransformation processes (Fast et al. 2006; Lin et al. 2004). In Protothaca staminea, the in vitro biotransformations mainly occur in DG tissues, then in gills and finally in mantle and adductor muscle. Very few biotransformations occur in the siphon (Fast et al. 2006). Similarly, Mactra chinensis carbamoylases are particularly localised in crystalline style (a rotating flexible rod mechanically breaking down algal cell in the stomach, Langdon \&Newell,1996) and in digestive gland (Lin et al. 2004).

So far, very few studies have been performed on Pacific oyster Crassostrea gigas and paralytic toxins (Artigas et al. 2007; Guéguen et al. 2008; Lassus et al. 2007). One of them reports that $C$. gigas digestive gland was incubated for $24 \mathrm{~h}$ with STX without any dcSTX formation (Artigas et al. 2007). As a natural consequence, oyster would not have any carbamoyl activity, contrary to some bivalve molluscs like Protothaca staminea and Spisula 
solidissima in North America and Mactra chinensis or Peronidia venulosa in Japan (Artigas et al. 2007).

Moreover, C. gigas oyster in vitro incubated with GTX1, 4, 2, 3 and C1, 2 led to a reduction of almost $10 \%$ of each analogue within 24 hours (Lin et al. 2004).

Blanco et al. (2003) propose an interesting approach to modelling the contamination and detoxification of blue mussels containing paralytic shellfish toxins. They tested different models taking into account biotransformations in the total flesh. This study was aiming at first to study the influence of biotransformations on the overall toxicity during oyster detoxification kinetics. For this, an original mathematical model taking into account the various toxins and their potential biotransformations was adjusted from data obtained in the digestive gland (DG) and in the other tissues (OT). In a second step, toxin transfers from DG to OT were investigated. Finally, an aggregated model was proposed and compared with model most frequently encountered in the literature, i.e. one- or two-compartment models. In the latter, the two compartments will be assigned to the digestive gland and remaining tissues, respectively. Models found in the literature that designate free toxins and toxins bound to oyster tissues as two different compartments will not be considered to avoid identifiability and discernability problems.

\section{Materials and methods}

\subsection{Biological materials}

Alexandrium minutum (AM89BM) and Skeletonema costatum (PBA855) were grown in $10 \mathrm{~L}$ culture vessels filled with sterilised sea water enriched with F/2 medium (Guillard 1975) 
. Both algal cultures were placed in thermoregulated rooms $\left(16 \pm 0.5{ }^{\circ} \mathrm{C}\right)$ with a diurnal photon density flux of $50 \pm 4 \mu$ moles $\mathrm{m}^{-2} \mathrm{~s}^{-1}$ and a $12 / 12$ light/dark cycle.

C. gigas oyster with a mean meat wet weight of $5.49 \pm 1.08 \mathrm{~g}$ (s.d., $\mathrm{n}=216$ ) were harvested in Bourgneuf Bay (France). They were acclimated at $16 \pm 0.5^{\circ} \mathrm{C}$ for 4 days prior to the experiment. Epibionts and other fouling organisms were discarded. The animals had no history of previous contamination by toxic microalgae.

\subsection{Experiments}

Oysters were placed in three $150 \mathrm{~L}$ raceways continuously supplied with natural sea water at $16.0 \pm 0.4{ }^{\circ} \mathrm{C}$. At each raceway outlet, a 'buffer tank' containing two immersed pumps ensured continuous water circulation and fluorescence recording. Toxic or non-toxic algal cultures were supplied to the experimental flume through the buffer tank and according to the fluorescence level detected by the fluorometer. The Turner Design fluorometer was connected to a PC via a data-logger to provide a permanent control of the peristaltic pump flow rate in close relationship with the range of fluorescence values forced by the user. Experimental conditions (duration, cell concentrations) during contamination and detoxification periods are summarised in Table 1. For toxin content analysis, six oysters were sampled (days $0,1,2,5$ and 7) from each raceway and then dissected in such a way that digestive glands were separated from other tissues. All six digestive glands were pooled before toxin extraction and the same procedure was applied to other remaining tissues.

\subsection{Chemical analysis}

Every sample was analysed three times by High Performance Liquid Chromatography coupled with fluorescence detection (HPLC-FLD) for further paralytic toxin quantification. Dissected oyster tissues were placed in a Büchner funnel for 1 hour to drain off the excess water. At the end of this process, they were ground and acidified in $0.1 \mathrm{~N} \mathrm{HCl}(2 \mathrm{v} / \mathrm{w})$. 
Homogenised meats were centrifuged for 15 minutes at $3,000 \mathrm{~g}$ and $4{ }^{\circ} \mathrm{C}$, and the $\mathrm{pH}$ adjusted to 3.0-3.5 with $6 \mathrm{~N} \mathrm{HCl}$. They were subsequently ultra-centrifuged for 15 minutes at 17,000 g and $4{ }^{\circ} \mathrm{C}$ and finally ultra-filtered (10,000 Da). Supernatants thus obtained were analysed. For PST extraction from toxic phytoplankton cells, $10 \mathrm{~mL}$ was sampled from experimental culture vessels and placed in glass tubes. These were then centrifuged for 15 minutes at 3,000 g and 4 ${ }^{\circ} \mathrm{C}$. Sedimented pellets were resuspended in $1 \mathrm{~mL}$ acetic acid $0.1 \mathrm{~N}$ and stored at $-80{ }^{\circ} \mathrm{C}$. They were then sonicated for 15 minutes. Finally, tubes were ultra-centrifuged for 15 minutes at $17,000 \mathrm{~g}$ and $4{ }^{\circ} \mathrm{C}$ and ultra-filtered on $0.2 \mu \mathrm{m}$ mesh size. Supernatant was then ready for analysis.

Analysis of PST was performed using Oshima's method (1995) with slight adaptations. Toxins were separated using reverse phase chromatography and a C8 column with a flow rate of $0.8 \mathrm{~mL} \min ^{-1}$. $\mathrm{pH}$ elution and column temperature were calibrated to optimise the separation of gonyautoxins GTX1, GTX2, GTX3, GTX4, dcGTX3 and dcGTX2. $\mathrm{C} 1$ and $\mathrm{C} 2$ toxins were then indirectly detected and quantified using prior acid hydrolysis of samples $\left(0.4 \mathrm{~N} \mathrm{HCl}\right.$ at $98{ }^{\circ} \mathrm{C}$ for 5 min; Masselin et al., 2001).

Toxin concentrations in either A. minutum cultures or in contaminated oysters were converted into pg equiv. STX cell ${ }^{-1}$ or into $\mu \mathrm{g}$ equiv. STX $100 \mathrm{~g}^{-1}$ of wet meat respectively by using Oshima’s conversion factors (Oshima, 1995).

\subsection{Modelling}

All models presented in this paper are structurally globally identifiable i.e. existence and uniqueness of all model parameters are demonstrated for our inputs and outputs. A summary of all text referenced models is given in Table 2. 


\subsubsection{Modelling biotransformations in digestive gland}

Different PST biotransformations in shellfish tissues were identified by Oshima in 1995 and were used in the present work to build a reference diagram (Figure 3). Only six toxic compounds were evidenced from chemical analysis performed on A. minutum (AM89BM), oyster DG and remaining tissues: GTX3, GTX2, C1, C2, dcGTX3 and dcGTX2. This result made it possible to simplify Figure 3 and to obtain 7 potential biotransformation pathways (Fig. 4).

A mathematical model can be deduced from Figure 4, provided toxin input to the DG and related biotransformation and elimination processes are considered.

$\frac{d[C 1]}{d t}=a_{C 1} \times C R \times[C 1]_{m}+E_{C 2 \rightarrow C 1}[C 2]-\left(H_{C 1 \rightarrow G T X 2}+k_{C 1}+\frac{d P}{d t}\right)[C 1]$

$\frac{d[C 2]}{d t}=a_{C 2} \times C R \times[C 2]_{m}-\left(E_{C 2 \rightarrow C 1}+H_{C 2 \rightarrow G T X 3}+k_{C 2}+\frac{d P}{d t}\right)[C 2]$

$\frac{d[G T X 2]}{d t}=a_{G T X 2} \times C R \times[G T X 2]_{m}+H_{C 1 \rightarrow G T X 2}[C 1]+E_{G T X 3 \rightarrow G T X 2}[G T X 3]-\left(H_{G T X 2 \rightarrow d c G T X 2}+k_{G T X 2}+\frac{d P}{d t}\right)[G T X 2]$

$\frac{d[G T X 3]}{d t}=a_{G T X 3} \times C R \times[G T X 3]_{m}+H_{C 2 \rightarrow G T X 3}[C 2]-\left(E_{G T X 3 \rightarrow G T X 2}+H_{G T X 3 \rightarrow d C G T X 3}+k_{G T X 3}+\frac{d P}{d t}\right)[G T X 3]$ 
$\frac{d[d c G T X 2]}{d t}=a_{d c G T X 2} \times C R \times[d c G T X 2]_{m}+H_{G T X 2 \rightarrow d c G T X 2}[G T X 2]+E_{d c G T X 3 \rightarrow d c G T X 2}[d c G T X 3]-\left(k_{d c G T X 2}+\frac{d P}{d t}\right)[d c G T X 2]$

$\frac{d[d c G T X 3]}{d t}=a_{d c G T X 3} \times C R \times[d c G T X 3]_{m}+H_{G T X 3 \rightarrow d c G T X 3}[G T X 3]-\left(E_{d c G T X 3 \rightarrow d c G T X 2}+k_{d c G T X 3}+\frac{d P}{d t}\right)[d c G T X 3]$

Tox $=0.3592 \times[$ GTX 2] $]+0.6379 \times[$ GTX 3$]+0.0060 \times[C 1]+0.0963 \times[C 2]+0.1538 \times[d c G T X 2]+0.3766 \times[d c G T X 3]$

with:

- [A]: concentration of compound A in shellfish, in $\mu \mathrm{g}$ per $100 \mathrm{~g}$ of wet meat

- $[\mathrm{A}]_{\mathrm{m}}$ : concentration of compound $\mathrm{A}$ in the medium, in $\mu \mathrm{g} \mathrm{L}$

- CR: shellfish clearance rate in L. $\mathrm{d}^{-1}$ per $100 \mathrm{~g}$ of wet meat

$-\mathrm{a}_{\mathrm{a}}$ : toxin retention coefficient in shellfish

- $\mathrm{H}_{\mathrm{a} \rightarrow \mathrm{b}}$ : hydrolysis of compound a toward compound $\mathrm{b}$ in $\mathrm{d}^{-1}$

- $E_{a \rightarrow b}$ : epimerisation of compound a toward compound $b$ in $d^{-1}$

- $\mathrm{k}_{\mathrm{a}}$ : detoxification coefficient of compound a in $\mathrm{d}^{-1}$

- P: body or tissue weight of shellfish

- Tox: overall toxicity expressed as $\mu \mathrm{g}$ eq. STX $100 \mathrm{~g}^{-1}$ meat.

As this study focussed on detoxification patterns, model inputs for DG are equal to zero $\left(\mathrm{a}_{\mathrm{a}} \times \mathrm{CR} \times[\mathrm{A}]_{\mathrm{m}}=0\right)$.

As tissue weights did not change throughout the experiment and considering the experimental conditions encountered, it will be assumed that $\frac{d P}{d t}=0$ 
Two new sub-models issued from the generic previous model were performed according to different constraints: the fit of the first one supposed that all hydrolysis and epimerisation coefficients were equal to zero and the second one was obtained by forcing an elimination coefficient identical for all toxic compounds: $\left(k_{C 2}=k_{C 1}=k_{G T X 2}=k_{G T X 3}=k_{d c G T X 2}=k_{d c G T X 3)}\right.$.

\subsubsection{Modelling biotransformations in remaining tissues and transfer from digestive gland to remaining tissues}

Biotransformations in other tissues (OT) were evaluated according to the same schedule than for DG except for toxin input, which is modified. In a first case, toxic compound input is equal to zero. In a second case, toxin input corresponds to the elimination of these compounds from the DG ( input $=k_{A, G D}[A]_{G D} \frac{W_{G D}}{W_{O T}}$ with $\mathrm{W}_{\mathrm{DG}}$ and $\mathrm{W}_{\mathrm{OT}}$ respectively the $\mathrm{DG}$ and OT weight in g). In a third case, only a part of toxic compound elimination is transferred from the DG toward other tissues (input $=k_{A, G D}[A]_{G D} \frac{W_{G D}}{W_{O T}} T_{A}$; with $\mathrm{T}_{\mathrm{A}}$ the relative ratio of toxin transfer rate from the DG to the other tissues for the compound A. Nine possible and identifiable scenarios of biotransformations and transfers were tested to define simultaneously the importance of biotransformation in remaining tissues and transfer from DG to OT. Inputs $[A]_{G D}$ were calculated from results obtained with DG3 model. The ratio $\frac{W_{G D}}{W_{O T}}$ is equal to 0.299. DG and remaining tissues represented 23 and $77 \%$ respectively of total body weight. The same models than for DG were tested on the total body burden. 


\subsubsection{Coefficient fitting}

Each coefficient adjustment was performed in a precise order to minimize the different criteria and therefore to respect all specific constraints (appendix 1). Models were set up using the Matlab 6.5 Simulink Library. The Matlab function which allows adjustment was based on Nelder-Mead algorithm (Lagarias et al 1998) under constraint. Coefficient fitting algorithm was performed according to a least square method which minimises the sum of squared errors (sse) between predicted values given by the model and data experimentally obtained. The minimization criterion itself was weigted by Oshima's coefficient (appendix 1) to obtain a mono-criterion indicator agreeing better with the toxicity.

\subsubsection{Comparison with literature data and with an aggregated model}

Thereafter, these models were compared to those found in the literature, i.e. : models taking into account one- or two compartments (1C1 and 2C models respectively) . Then, an aggregated model was proposed (model 1C2). Rather than using the different compounds kinetics calculated from the different STX analogues, a first order equation was defined in such a way that the elimination rate " $k$ " integrates the weight of toxic analogues ratio upon the overall elimination rate, or $: \frac{d T o x}{d t}=-k$ Tox with $\mathrm{k}=\mathrm{f}([$ main initial toxic compounds with dissimilar kinetics)

This model focuses on overall toxicity increase and, at the same time, integrates GTX3 and

GTX2 initial ratio in the following expression of $\mathrm{k}: k=\alpha \times \frac{[G T X 3]_{i}}{[G T X 3]_{i}+[G T X 2]_{i}}+\beta$ where Tox is 
the toxicity in $\mu \mathrm{g}$ equiv. STX for $100 \mathrm{~g}$ of flesh, $\mathrm{k}$ the detoxification rate in $\mathrm{d}^{-1}$ and $[G T X 2]_{i}$ and $[G T X 3]_{i}$ the initial concentrations.

To be able to compare all different models, the equation 7 was applied to observed data to obtain the global toxicity (expressed in $\mu \mathrm{g}$ STX equiv. for $100 \mathrm{~g}$ of flesh) corresponding to our new modelling output. The fitness accuracy of these models was estimated using sse and rmse according to the usual definitions.

\section{Results}

\subsection{Observations}

Figure 5 A represents the oyster toxin profile on the last day of contamination and for the three experiments (RC1, RC2, RC3). No significant difference was observed for either GTX3, C2 or C1. However, a significant difference in the proportion of GTX2 was noted (ANOVA, $\mathrm{p}=0.006$ ). In a similar way, dcGTX3 and dcGTX2 displayed significantly different proportions in each of the three experiments (ANOVA, $\mathrm{p}=0.0005$ and $\mathrm{p}=0.0186$ respectively). Generally speaking, the proportion of the different compounds found in oyster at the end of the contamination phase by A. minutum sorts the following profile: GTX3 is the main compound and represents $45.5 \pm 5.5 \%$ (mean \pm s.d.) of the toxin content expressed in $\mu$ g per 100 g meat, GTX2: $18.3 \pm 7.5 \%$ (between 17 and $29 \%$ for RC2 and RC3 and between 7 and $9 \%$ for RC1), C2: $17.6 \pm 9.8 \%, \mathrm{C} 1: 15.4 \pm 5.5 \%$, dcGTX3: $1.5 \pm 5.5 \%$ and dcGTX2: $1.7 \pm$ $1.1 \%$ (Figure 5B). The proportions observed in contaminated oysters are very different from those observed in A. minutum cultures, namely for GTX3, GTX2 and C1 (ANOVA, p= 0.0057, $\mathrm{p}=0.045$ and $\mathrm{p}=0.0363$; fig. 5B). 
The above results do not consider toxicities expressed as STX equivalent. Moreover, it is noteworthy that GTX3 is the most represented compound in oyster meat as well as the most toxic among all other STX analogues detected in this experiment. During detoxification, GTX2 and GTX3 represented more than $90 \%$ of toxicity expressed as STX equivalent per $100 \mathrm{~g}$ of shellfish meat. As a consequence, to ensure an easier reading, all graphs obtained during modelling trials will only represent GTX2 and GTX3.

\subsection{Modelling}

\subsubsection{Digestive gland}

Adjustments for the three different models are applied to each data set (RC1, RC2 and RC3). Quite different coefficients were fitting for each experiment (data not shown). Moreover the main biotransformation pattern may differ according to the type of experiment. The only type of biotransformation occurring in each of the three experiments is GTX3 epimerization into GTX2 but this coefficient differs greatly between experiments $\left(0.88 \mathrm{~d}^{-1}\right.$ for $\mathrm{RC} 1,0.036 \mathrm{~d}^{-1}$ for $\mathrm{RC} 2$ and $0.125 \mathrm{~d}^{-1}$ for RC3). Besides, this type of biotransformation is not always predominant.

To work on a single data set allowing a higher degree of adjustment robustness, the three data sets were put together as combined series (Table 4, Figure 6). Rmse obtained with data sets in combined series are of the same order of magnitude as rmse for experiments $\mathrm{RC} 1$ and RC3 and with a fitness accuracy slightly worse than in experiment RC2. In the same way, sse of the combined series are of the same order of magnitude as the sum of each sse 
considered individually, which indicates that the adjustments obtained for each experiment are correct.

It should be noted that the apparent kinetics of GTX2 seem slower than those of other compounds, especially GTX3. It should be remembered that more than $90 \%$ of $C$. gigas DG toxin content, once contaminated by A. minutum (AM89BM), is linked to GTX3 and GTX2 detection in shellfish meat. In the early steps of the detoxification period $\left(\mathrm{d}_{0}\right)$, GTX3 contributes more than $70 \%$ of the toxin body burden whereas for GTX2 it is less than $20 \%$. Throughout detoxification, the GTX3 decrease will be faster than that of GTX2, which progressively induces an increase in the GTX2 contribution to the total toxin body burden. $A$. minutum-contaminated oyster detoxification seems relatively rapid, especially because the overall detoxification kinetics are mainly ruled - at the beginning - by GTX3 kinetics.

Thus, this new data set evidenced a $9 \%$ adjustment improvement when using the model which considered biotransformations (DG2). Moreover, when all detoxification coefficients are forced equivalent (DG3), the rmse is better than when these coefficients are free (rmse=34.93 and 36.34 respectively). In this case, highlighted biotransformations are the three epimerizations of C2 into C1, GTX3 into GTX2 and dcGTX3 into dcGTX2. The DG3 model was retained for all further modelling with other tissues.

\subsubsection{Remaining tissues and total flesh}

Different models were adjusted to remaining tissues data in combined series, to obtain more robust adjustment results, as already done with DG. The first results obtained with OT data confirmed the no-significant role played by biotransformations (data not shown). Similar sse were observed and the best rmse were obtained without biotransformation either for remaining tissues or for total flesh. For example, the relative difference between OT1 and 
OT2 sse (Table 2) is less than $0.5 \%$ and and this difference reach $6.5 \%$ for rmse. Secondly, we tested toxic compounds specific inputs to evaluate the incidence of DG to OT transfer for the different scenarios. Three types of inputs were considered: (i) input with null value, i.e. no detectable transfer between DG and other tissues (OT1), (ii) all toxic compounds eliminated from DG are redirected toward other tissues (OT3), (iii) only a certain portion of toxic compounds is transferred from DG toward the other tissues (OT4). These least comments are for the "none biotransformation" assumption but also are in agreement with the other cases (not shown).

The fitting of the OT1 and OT4 models are very closed. The sse difference is less than $1 \%$. On the other hand, the squared sum of error is $6 \%$ higher for the OT3 model.

From these results, it seems that toxin elimination from the DG is not totally redirected toward the other organs. It can therefore be suggested that most toxins detected in oyster DG are damaged or eliminated via the digestive tract without being incorporated into the other tissues.

\subsubsection{Comparison and aggregation}

All models tested were compared according to the sse criteria and results are presented in Table 5

First of all, predicting the six toxic compound kinetics by organs (DG3+OT1) or on total flesh did not lead to a significant gain on the quality of toxicity estimation with regard to models only based upon overall toxicity estimation. Similar results were obtained with either the aggregation in one toxicity state by organs (2C) of the six states corresponding to toxic analogues or with the global model covering all twelve states. In both cases, the best fit was observed with no transfer between DG and OT. Satisfying results were obtained with a simple 
one-compartment model (1C) even if a decrease in fitness quality in comparison with the twocompartments model (2C) was observed.

The best sse and rmse criteria were obtained with the one-compartment model which considers a detoxification rate depending on GTX3 and GTX2 ratio, i.e : $k=0.558 \times \frac{[G T X 3]_{i}}{[G T X 3]_{i}+[G T X 2]_{i}}-0.1126$ where $[G T X 3] i$ and $[$ GTX2]i represent the initial GTX3 and GTX2 concentrations observed at the end of the contamination phase and therefore at the beginning of the detoxification phase. The squared sum of deviations was 7327 for this model and, considering only these two analogues, ensured a better fit than that obtained with classical compartment models (Figure 7). This model is equivalent to a simple onecompartment model by experiments but with an elimination rate determined by its specific ratio of initial GTX3 and sum of GTX3 and GTX2. So with this model, elimination rate for were respectively of $0.27,0.32$ and 0.26 for the three successive combined experiments.

\section{Discussion}

In this work, toxic profiles of $C$. gigas oyster and A. minutum microalga revealed different patterns. Such differences between toxin producers and higher links in the food chain are often observed (Asakawa et al. 2006; Ichimi et al. 2001; Oshima 1995). In Pacific oyster, carbamate toxins are present in higher proportions than $\mathrm{C}$ toxins. This observation seems to be a common pattern in molluscan shellfish (Oshima 1995; Ichimi et al. 2001). Such a difference could result from three phenomena acting separately or in combination: (i) toxic compound assimilation rates could be different, (ii) some compounds could be rapidly transformed as soon as they penetrate oyster DG, (iii) elimination of toxins could be compound-specific. 
Combining the three data sets as a combined series provides both a single bigger data set and a more reliable fit. Biotransformation consideration in the DG allows a better fit. However, it is difficult to conclude definitively that biotransformations always occur in $C$. gigas DG. The same observation can be made on the other tissues. In fact, considering biotransformation processes or not does not seem to generate real changes in model fit especially for remaining tissues. These remarks are in agreement with Lin et al. (2004) and Fast et al. (2006) whose results indicate that stomach and digestive glands are favoured sites for biotransformations. Yet it can be stated that, in this particular case, biotransformations are not playing an important role in detoxification kinetics.

An interesting observation relates to toxin transfer from the DG towards other tissues. The most usual scheme considers that an important part of the toxins eliminated by the DG are transferred towards all other tissues. However, this mechanism does not really fit with our data sets. Very few transfers from DG to other tissues seem to occur during detoxification, which could indicate that almost all toxic compounds present in the DG are first trapped in this organ before being hydrolysed or eliminated via the intestinal tract, as suggested by Blanco et al. (1997). The way the toxins are transferred from one tissue to another is still not clear but some authors state that haemocytes could be the key parameter in this process (Galimany et al. 2008; Suzuki et al. 2005).

Blanco et al. (2003) propose a model which considers the analogues GTX1, GTX2, GTX3 and GTX4 in mussel Mytilus galloprovincialis following contamination with Alexandrium tamarense. They observed that differentiation of each compound does not play any significant role in the relative contribution of GTX. However, in the present work, a certain improvement is achieved if each compound is considered individually. Taking into account PST differentiation, rather than the overall evaluation of toxicity, ensures a better prediction of detoxification kinetics. 
GTX3 and GTX2 account for $90 \%$ of the toxin content in PST-contaminated oyster and the overall detoxification kinetics clearly result from the different kinetics related to these two analogues. GTX3 will be eliminated more rapidly than GTX2. With regard to total meat detoxification coefficients obtained with the three data sets in combined series, it can be noted that the more the GTX3 proportion increases (when compared to GTX3 + GTX2 um), the faster the detoxification time. The best adjustment is obtained when the model depends on the ratio of GTX3 initial concentration on the sum of GTX3 and GTX2

This kind of result is believed to offer a great help for the management of contaminated areas. In fact, bivalve mollusc toxicity will be analysed to know whether the health threshold is exceeded. If the analysis is operated according to Lawrence's official method, the amount of each toxic compound is known and it is therefore possible to use a detoxification model taking into account all STX analogues. However, this model must be validated with a new data set. Finally, this model only applies to the particular case of Crassostrea gigas contamination by Alexandrium minutum (strain AM89BM) so it will be worth investigating the detoxification kinetics of oyster contaminated by another Alexandrium species or strain, featuring another toxin profile. Similarly, further studies are needed with other shellfish species. Indeed, there are strong differences in biotransformation capabilities within molluscan shellfish at the species or family level (Lin et al. 2004). For instance, abalone Haliotis midae displays strong biotransformation potential (Pitcher et al. 2001) unlike Mytilus edulis and Crassostrea gigas (Jaime et al. 2007). When an important biotransformation process really occurs in mollusc soft parts, detoxification kinetics can be strongly modified. Following the present study, it would be worth determining why GTX2 kinetics are slower than those of GTX3. Some previous works (Gueguen et al. 2008) demonstrated the effect of non-toxic algal food upon detoxification kinetics. Although this was not considered in the 
present study, further investigations could be carried out by adapting the mathematical expression $\mathrm{k}$ in order to incorporate this variable in our model.

To conclude, an aggregated one-compartment model (corresponding to total flesh) with an elimination coefficient depending upon GTX3 and GTX2 initial concentrations seems the most appropriate one to correctly describe the detoxification kinetics of A. minutumcontaminated oyster. This last model should be easily completed to integrate environmental variables not yet investigated in this study. New experiments would be interesting to confirm our conclusions. This modelling and fitting approach described here could be particularly relevant for mollusks presenting recognized biotransformations, as clams for example.

\section{Appendix 1}

The present algorithm is adapted to the parametric estimation of equations (1) to (6) with specific constraints such as : initial conditions repeatedly reset, abnormal data deleted (missing data), limited parametric range, multi-outputs estimation with Oshima coefficients weighting ...

Coefficient fitting is performed by minimization of least squared criteria on either observed or estimated values associated with ordinary differential equations solving in progressive steps such as :

\section{First step:}

$\frac{d C_{2}}{d t}=-d_{C 2} C_{2}$

$\min J_{C 2}=\sum_{i=1}^{n_{C 2}}\left(C_{2, i}-C_{2, i}^{*}\right)^{2}$ with $C_{2}^{*}: C_{2}$.measurements, $\mathrm{n}_{\mathrm{C} 2}:$ number of normal $C_{2}^{*}$ data 
$\frac{d C_{1}}{d t}=E_{C 2 \rightarrow C 1} C_{2}-d_{C 1} C_{1}$

$\frac{d G T X_{3}}{d t}=H_{C 2 \rightarrow G T X 3} C_{2}-d_{G T X 3} G T X_{3}$

$\min J_{C 1 / G T X 3}=0.6379 \frac{n_{T}}{n_{G T X 3}} \sum_{i=1}^{n_{G T X 3}}\left(G T X_{3, i}-G T X_{3, i}^{*}\right)^{2}+0.006 \frac{n_{T}}{n_{C 1}} \sum_{i=1}^{n_{C 1}}\left(C_{1, i}-C_{1, i}^{*}\right)^{2}$, with $n_{T}: \max \left(n_{A}\right), n_{A}:$

number of normal data for compound A.

$E_{C 2 \rightarrow C 1}+H_{C 2 \rightarrow G T X 3} \leq d_{C 2}$

Therefore, what remains to be determined is: $E_{C 2 \rightarrow C 1}, H_{C 2 \rightarrow G T X 3}$ and $k_{C 2}=d_{C 2}-H_{C 2 \rightarrow G T X 3}-E_{C 2 \rightarrow C 1}$

Third step:

$$
\begin{aligned}
& \frac{d G T X_{2}}{d t}=H_{C 1 \rightarrow G T X 2} C_{1}+E_{G T X 3 \rightarrow G T X 2}-d_{G T X 2} G T X_{2} \\
& \frac{d d c G T X_{3}}{d t}=H_{G T X 3 \rightarrow d c G T X 3} G T X_{3}-d_{d c G T X 3} G T X_{3} \\
& \min J_{G T X 2 / d c G T X 3}=0.3592 \frac{n_{T}}{n_{G T X 2}} \sum_{i=1}^{n}\left(G T X_{2, i}-G T X_{2, i}^{*}\right)^{2}+0.3766 \frac{n_{T}}{n_{d c G T X 3}} \sum_{i=1}^{n}\left(d c G T X_{3, i}-d c G T X_{3, i}^{*}\right)^{2} \\
& H_{C 1 \rightarrow G T X 2} \leq d_{C 1} \\
& E_{G T X 3 \rightarrow G T X 2}+H_{G T X 3 \rightarrow d c G T X 3} \leq d_{G T X 3}
\end{aligned}
$$

Therefore, what remains to be determined is: $H_{C 1 \rightarrow G T X 2}, E_{\text {GTX3 } \rightarrow \text { GTX2 }}, H_{\text {GTX3 } \rightarrow d c G T X 3}$, $k_{C 1}=d_{C 1}-H_{C 1 \rightarrow G T X 2}, k_{G T X 3}=d_{G T X 3}-H_{G T X 3 \rightarrow d c G T X 3}-E_{G T X 3 \rightarrow G T X 2}$

\section{Fourth step:}

$\frac{d d c G T X_{2}}{d t}=H_{G T X 2 \rightarrow d c G T X 2} G T X_{2}+E_{d c G T X 3 \rightarrow d c G T X 2} d c G T X_{3}-k_{d c G T X 2} G T X_{2}$

$\min J_{d c G T X 2}=\sum_{i=1}^{n}\left(d c G T X_{2, i}-d c G T X_{2, i}^{*}\right)^{2}$ 
$E_{d c G T X 3 \rightarrow d c G T X 2} \leq d_{d c G T X 3}$

$H_{G T X 2 \rightarrow d c G T X 2} \leq d_{G T X 2}$

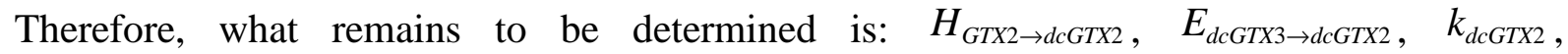
$k_{d c G T X 2}=d_{d c G T X 2}-H_{G T X 2 \rightarrow d c G T X 2}, k_{d c G T X 3}=d_{d c G T X 3}-E_{d c G T X 3 \rightarrow d c G T X 2}$

This algorithm was adapted for the sub-model with a same elimination rate (not shown).

Evaluation of model fitness is performed by a classical rmse calculation of the specific sse (noted SSE*).

$S S E^{*}=\sum_{i=1}^{6} \alpha_{i} \frac{n_{T}}{n_{i}} S S E_{i}$

with $S S E_{i}$ : squared sum of deviations between measured points and modelled points for compound iA, $\alpha_{i}$ : Oshima coefficient for compound i defined in equation (7).

\section{Literature cited}

Amzil Z, Fresnel J, Le Gal D, Billard C. 2001. Domoic acid accumulation in French shellfish in relation to toxic species of Pseudo-nitzschia multiseries and P-pseudodelicatissima. Toxicon 39(8):1245-1251.

Artigas ML, Vale PJV, Gomes SS, Botelho MJ, Rodrigues SM, Arnorim A. 2007. Profiles of paralytic shellfish poisoning toxins in shellfish from Portugal explained by carbamoylase activity. Journal of Chromatography A 1160(1-2):99-105.

Asakawa M, Beppu R, Ito K, Tsubota M, Takayama H, Miyazawa K. 2006. Accumulation of paralytic shellfish poison (PSP) and biotransformation of its components in oysters 
Crassostrea gigas fed with the toxic dinoflagellate Alexandrium tamarense. Journal of the Food Hygienic Society of Japan 47(1):A28-A32.

Blanco J, Fernandez ML, Miguez A, Morono A. 1999. Okadaic acid depuration in the mussel Mytilus galloprovincialis: one- and two-compartment models and the effect of environmental conditions. Marine Ecology-Progress Series 176:153-163.

Blanco J, Morono A, Franco J, Reyero MI. 1997. PSP detoxification kinetics in the mussel Mytilus galloprovincialis. One- and two-compartment models and the effect of some environmental variables. Marine Ecology-Progress Series 158:165-175.

Blanco J, Reyero MI, Franco J. 2003, Kinetics of accumulation and transformation of paralytic shellfish toxins in the blue mussel Mytilus galloprovincialis. Toxicon 42: $777-784$

Bricelj VM, Shumway SE. 1998. Paralytic shellfish toxins in bivalve molluscs: occurrence, transfer kinetics and biotransformation. Fisheries Science 6(4):315-383.

Choi MC, Yu PKN, Hsieh DPH, Lam PKS. 2006. Trophic transfer of paralytic shellfish toxins from clams (Ruditapes philippinarum) to gastropods (Nassarius festivus). Chemosphere 64(10):1642-1649.

D’Errico J 2006 fminsearchbnd function http://www.mathworks.com/matlabcentral/fileexchange/8277-fminsearchbnd EEC (1991) Directive (EEC) No 492/1991 of 15 July 1991 laying down the health conditions for the production and the placing on the market of live bivlave molluscs. $19 \mathrm{p}$

Fast MD, Cembella AD, Ross NW. 2006. In vitro transformation of paralytic shellfish toxins in the clams Mya arenaria and Protothaca staminea. Harmful Algae 5(1):79-90.

Galimany E, Sunila I, Hegaret H, Ramon M, Wikfors GH. 2008. Experimental exposure of the blue mussel (Mytilus edulis, L.) to the toxic dinoflagellate Alexandrium fundyense: Histopathology, immune responses, and recovery. Harmful Algae 7(5):702-711. 
Gueguen M, Bardouil M, Baron R, Lassus P, Truquet P, Massardier J, Amzil Z. 2008. Detoxification of Pacific oyster Crassostrea gigas fed on diets of Skeletonema costatum with and without silt, following PSP contamination by Alexandrium minutum. Aquatic Living Resources 21(1):13-20.

Guillard, R.R.L. 1975. Culture of phytoplankton for feeding marine invertebrates. pp 26-60. In Smith W.L. and Chanley M.H (Eds.) Culture of Marine Invertebrate Animals. Plenum Press, New York, USA.

Haberkorn H, Lambert C, Le Goïc N, Guéguen M, Moal J, Palacios E, Lassus P, Soudant P. 2010. Effects of Alexandrium minutum exposure upon physiological and hematological variables of diploid and triploid oysters, Crassostrea gigas. Aquatic Toxicology 97(2):96-108.

Hallegraeff GM. 1995. 1. Harmful algal blooms: a global overview. In: Hallegraeff GM, editor. Manual on Harmful Marine Microalgae: IOC Manuals and Guides $\mathrm{N}^{\circ} 33$ UNESCO. p 1-22.

Ichimi K, Suzuki T, Yamasaki M. 2001. Non-selective retention of PSP toxins by the mussel Mytilus galloprovincialis fed with the toxic dinoflagellate Alexandrium tamarense. Toxicon 39(12):1917-1921.

Jaime E, Gerdts G, Luckas B. 2007. In vitro transformation of PSP toxins by different shellfish tissues. Harmful Algae 6(3):308-316.

Jiang TJ, Niu T, Xu YX. 2006. Transfer and metabolism of paralytic shellfish poisoning from scallop (Chlamys nobilis) to spiny lobster (Panulirus stimpsoni). Toxicon 48(8):988994.

Jin D, Thunberg E, Hoagland P. 2008. Economic impact of the 2005 red tide event on commercial shellfish fisheries in New England. Ocean \& Coastal Management 51(5):420-429. 
Kvitek RG, Goldberg JD, Smith GJ, Doucette GJ, Silver MW. 2008. Domoic acid contamination within eight representative species from the benthic food web of Monterey Bay, California, USA. Marine Ecology-Progress Series 367:35-47.

Lagarias JC, Reeds J, Wright MH, wright PE. 1998. Convergence properties of the NelderMead simplex method in low dimensions. Society for Industrial and Applied Mathematics 9(1):112-147.

Langdon C, Newell RIE, 1996. Digestion and nutrition in larvae and adults. In: The eastern oyster Crassostrea virginica. Kennedy V.S and Newell R.I.E. (Eds.). Maryland Sea Grant College.

Lassus P, Bardouil M, Baron R, Berard JB, Masselin P, Truquet P, Pitrat JP. 2005. Improving detoxification efficiency of PSP contaminated oysters (Crassostrea gigas Thunberg). Aquaculture Europe:3-6.

Lassus P, Gowland D, McKenzie D, Kelly M, Braaten B, Marcaillou-Martin C, Blanco J. 2007 Industrial scale detoxification of phycotoxin-contaminated shellfish: myth or reality?;.In : Proceedings of the $6^{\text {th }}$ Internat.Conf.Molluscan Shellfish Safety, Blenheim, New Zealand,

Ledoux M, Bardouil M, Nezan E, Erard E. Field and experimental studies of shellfish contaminated by Alexandrium minutum strain. In: Fremy JM, et al., editor; 1991; Paris, Centre national d'études vétérinaires et alimentaires. p 43-51.

Lin HP, Cho Y, Yashiro H, Yamada T, Oshima Y. 2004. Purification and characterization of paralytic shellfish toxin transforming enzyme from Mactra chinensis. Toxicon 44(6):657-668.

Masselin P, Amzil Z, Abadie E, Nézan E, Le Bec C, Chiantella C, Truquet P. Paralytic shellfish poisoning on the French Mediterranean coast in the autumn 1988: 
Alexandrium tamarense complex (Dinophycea) as causative agent. In: Hallegraeff GM, Blackburn SI, Bolch CJ, Lewis RJ, editors; 2000. JOC-UNESCO. p 407-410.

Oshima Y. Chemical and enzymatic transformation of paralytic shellfish toxins in marine organisms. In: Lavoisier Publishing ILP, editor; 1995. Lassus, P., Arzul, G., Erard-Le Denn, E., Gentien, P., Marcaillou-Le Baut, C.

Pitcher GC, Franco JM, Doucette GJ, Powell CL, Mouton A. 2001. Paralytic shellfish poisoning in the abalone Haliotis midae on the west coast of South Africa. Journal of Shellfish Research 20(2):895-904.

Sato S, Sakai R, Kodama M. 2000. Identification of thioether intermediates in the reductive transformation of gonyautoxins into saxitoxins by thiols. Bioorganic \& Medicinal Chemistry Letters 10(16):1787-1789.

Sechet V, Berard JB, Bohec M, Bougaran G, Carré C, Masselin P, Truquet P. Growth and toxicity of Alexandrium catenella isolated from Thau lagoon (France) cultured in stirred tank bioreactors. In: Villarba A, Reguera B, Romalde JL, Bairas R, editors; 2003. p 135-144.

Silvert WL, Cembella AD. 1995. Dynamic modeling of phycotoxin kinetics in the blue mussel, Mytilus edulis, with implication for other marine-invertebrates. Canadian Journal of Fisheries and Aquatic Sciences 52(3):521-531.

Smith EA, Grant F, Ferguson CMJ, Gallacher S. 2001. Biotransformations of paralytic shellfish toxins by bacteria isolated from bivalve molluscs. Applied and Environmental Microbiology 67(5):2345-2353.

Suzuki T, Igarashi T, Ichimi K, Watai M, Suzuki M, Ogiso E, Yasumoto T. 2005. Kinetics of diarrhetic shellfish poisoning toxins, okadaic acid, dinophysistoxin-1, pectenotoxin-6 and yessotoxin in scallops Patinopecten yessoensis. Fisheries Science 71(4):948-955. 
Van Egmond HP, Aune T, Lassus P, Speijers GJA, Waldock M. 1993. Paralytic and diarrhoeic shellfish poisons occurrence in Europe toxicity, analysis and regulation. Journal of Natural Toxins 2:41-83. 


\section{Appendix 1}

The present algorithm is adapted to the parametric estimation of equations (1) to (6) with specific constraints such as : initial conditions repeatedly reset, abnormal data deleted (missing data), limited parametric range, multi-outputs estimation with Oshima coefficients weighting ...

Coefficient fitting is performed by minimization of least squared criteria on either observed or estimated values associated with ordinary differential equations solving in progressive steps such as :

\section{First step:}

$\frac{d C_{2}}{d t}=-d_{C 2} C_{2}$

$\min J_{C 2}=\sum_{i=1}^{n_{C 2}}\left(C_{2, i}-C_{2, i}^{*}\right)^{2}$ with $C_{2}^{*}: C_{2}$. measurements, $\mathrm{n}_{\mathrm{C} 2}:$ number of normal $C_{2}^{*}$ data

\section{Second step:}

$\frac{d C_{1}}{d t}=E_{C 2 \rightarrow C 1} C_{2}-d_{C 1} C_{1}$

$\frac{d G T X_{3}}{d t}=H_{C 2 \rightarrow G T X 3} C_{2}-d_{G T X 3} G T X_{3}$

$\min J_{C 1 / G T X 3}=0.6379 \frac{n_{T}}{n_{G T X 3}} \sum_{i=1}^{n_{G T X 3}}\left(G T X_{3, i}-G T X_{3, i}^{*}\right)^{2}+0.006 \frac{n_{T}}{n_{C 1}} \sum_{i=1}^{n_{C 1}}\left(C_{1, i}-C_{1, i}^{*}\right)^{2}$, with $n_{T}: \max \left(n_{A}\right), n_{A}:$

number of normal data for compound A.

$E_{C 2 \rightarrow C 1}+H_{C 2 \rightarrow G T X 3} \leq d_{C 2}$

Therefore, what remains to be determined is: $E_{C 2 \rightarrow C 1}, H_{C 2 \rightarrow G T X 3}$ and $k_{C 2}=d_{C 2}-H_{C 2 \rightarrow G T X 3}-E_{C 2 \rightarrow C 1}$

Third step:

$$
\begin{aligned}
& \frac{d G T X_{2}}{d t}=H_{C 1 \rightarrow G T X 2} C_{1}+E_{G T X 3 \rightarrow G T X 2}-d_{G T X 2} G T X_{2} \\
& \frac{d d c G T X_{3}}{d t}=H_{G T X 3 \rightarrow d c G T X 3} G T X_{3}-d_{d c G T X 3} G T X_{3} \\
& \min J_{G T X 2 / d c G T X 3}=0.3592 \frac{n_{T}}{n_{G T X 2}} \sum_{i=1}^{n}\left(G T X_{2, i}-G T X_{2, i}^{*}\right)^{2}+0.3766 \frac{n_{T}}{n_{d c G T X 3}} \sum_{i=1}^{n}\left(d c G T X_{3, i}-d c G T X_{3, i}^{*}\right)^{2} \\
& H_{C 1 \rightarrow G T X 2} \leq d_{C 1}
\end{aligned}
$$


$E_{G T X 3 \rightarrow G T X 2}+H_{G T X 3 \rightarrow d c G T X 3} \leq d_{G T X 3}$

Therefore, what remains to be determined is: $H_{C 1 \rightarrow G T X 2}, E_{\text {GTX3 } \rightarrow \text { GTX2 }}, H_{\text {GTX3 } \rightarrow d c G T X 3}$, $k_{C 1}=d_{C 1}-H_{C 1 \rightarrow G T X 2}, k_{G T X 3}=d_{G T X 3}-H_{G T X 3 \rightarrow d c G T X 3}-E_{G T X 3 \rightarrow G T X 2}$

Fourth step:

$\frac{d d c G T X_{2}}{d t}=H_{G T X 2 \rightarrow d c G T X 2} G T X_{2}+E_{d c G T X 3 \rightarrow d c G T X 2} d c G T X_{3}-k_{d c G T X 2} G T X_{2}$

$\min J_{d c G T X 2}=\sum_{i=1}^{n}\left(d c G T X_{2, i}-d c G T X_{2, i}^{*}\right)^{2}$

$E_{d c G T X 3 \rightarrow d c G T X 2} \leq d_{d c G T X 3}$

$H_{G T X 2 \rightarrow d c G T X 2} \leq d_{G T X 2}$

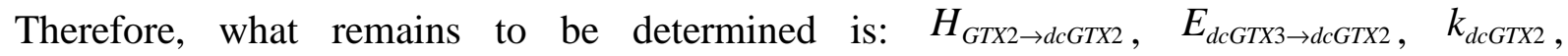
$k_{d c G T X 2}=d_{d c G T X 2}-H_{G T X 2 \rightarrow d c G T X 2}, k_{d c G T X 3}=d_{d c G T X 3}-E_{d c G T X 3 \rightarrow d c G T X 2}$

This algorithm was adapted for the sub-model with a same elimination rate (not shown).

Evaluation of model fitness is performed by a classical rmse calculation of the specific sse (noted SSE*).

$S S E^{*}=\sum_{i=1}^{6} \alpha_{i} \frac{n_{T}}{n_{i}} S S E_{i}$

with $S S E_{i}$ : squared sum of deviations between measured points and modelled points for compound iA, $\alpha_{i}$ : Oshima coefficient for compound i defined in equation (7). 
Table 1: Experimental conditions during oyster contamination by Alexandrium minutum and detoxification by Skeletonema costatum. RC: raceway.

\begin{tabular}{llllll}
\hline Experiment & $\begin{array}{l}\text { Cell } \\
\text { concentration } \\
\left(\text { cells mL } \mathrm{mL}^{-1}\right)\end{array}$ & $\begin{array}{l}\text { Contamination } \\
\text { Duration } \\
\text { (days) }\end{array}$ & $\begin{array}{l}\text { Cell } \\
\text { concentration } \\
\left.(\text { cells mL })^{-1}\right)\end{array}$ & $\begin{array}{l}\text { Detoxification } \\
\text { Duration } \\
\text { (days) }\end{array}$ & $\begin{array}{l}\text { Sampling } \\
\text { days }\end{array}$ \\
\hline $\mathrm{RC} 1$ & 2,000 & 5 & 2,000 & 7 & $0,1,2,5,7$ \\
$\mathrm{RC} 2$ & 200 & 10 & 2,000 & 7 & $0,1,2,5,7$ \\
$\mathrm{RC} 3$ & 200 & 13 & 2,000 & 8 & $0,1,2,3,4$, \\
& & & & 5,8 \\
\hline
\end{tabular}


Table 2: Name and description of the different models referenced in the text

DG: Digestive gland OT: other tissues TF : Total Flesh (DG + OT)

\begin{tabular}{|c|c|c|c|c|c|}
\hline Model name & Tissues & Input & Biotransformations & Detoxification rates & Aims \\
\hline DG1 & DG & No & No & Free & Biotransformations \\
\hline DG2 & DG & No & Free & Free & in DG and OT \\
\hline DG3 & DG & No & Free & Constant & \\
\hline OT1 & OT & No & No & Free & \\
\hline OT2 & OT & No & Free & Free & \\
\hline OT1 & OT & No & No & Free & Transfer from DG \\
\hline OT3 & OT & $\begin{array}{l}\text { Total } \\
\text { from } \\
\text { DG3 }\end{array}$ & No & Free & to OT \\
\hline OT4 & OT & $\begin{array}{l}\text { Free } \\
\text { from } \\
\text { DG3 }\end{array}$ & No & Free & \\
\hline $2 \mathrm{C} 1$ & $\begin{array}{c}\text { DG \& OT } \\
2 \text { compartments }\end{array}$ & No & No & Free & Aggregation \\
\hline $2 \mathrm{C} 2$ & $\begin{array}{c}\mathrm{TF} \\
2 \text { compartments }\end{array}$ & No & No & Free & \\
\hline $1 \mathrm{C} 1$ & $\begin{array}{c}\mathrm{TF} \\
1 \text { compartment }\end{array}$ & No & No & Free & \\
\hline $1 \mathrm{C} 2$ & $\begin{array}{c}\mathrm{TF} \\
1 \text { compartment }\end{array}$ & No & No & Free & \\
\hline
\end{tabular}


Table 3: Coefficients estimated, sum of squared errors (sse) and the root mean square error (rmse) by fitting the models implemented on the combined data of digestive gland.

\begin{tabular}{lrrr}
\hline Model & DG1 & DG2 & \multicolumn{1}{c}{ DG3 } \\
Biotransformation & & 0.241 & 0.024 \\
$\mathrm{E}_{\mathrm{C} 2 \rightarrow \mathrm{C} 1}$ & & 0.104 & 0.088 \\
$\mathrm{E}_{\mathrm{GTX} 3 \rightarrow \mathrm{GTX} 2}$ & & 0.328 & 0.081 \\
$\mathrm{E}_{\mathrm{dcGTX} \rightarrow \mathrm{dcGTX} 2}$ & 0.003 & 0 \\
$\mathrm{H}_{\mathrm{C} 2 \rightarrow \mathrm{GTX} 3}$ & & 0 & 0 \\
$\mathrm{H}_{\mathrm{GTX} 3 \rightarrow \mathrm{dcGTX} 3}$ & & 0.022 & 0 \\
$\mathrm{H}_{\mathrm{C} 1 \rightarrow \mathrm{GTX} 2}$ & 0 & 0 \\
$\mathrm{H}_{\mathrm{GTX} 2 \rightarrow \mathrm{dcGTX} 2}$ & & & \\
Detoxification rate & & 0.403 & \\
$\mathrm{k}_{\mathrm{C} 1}$ & 0.190 & & \\
& & 0.025 & \\
$\mathrm{k}_{\mathrm{C} 2}$ & 0.269 & 0.283 & \\
$\mathrm{k}_{\mathrm{GTX} 2}$ & 0.139 & 0.231 & 0.245 \\
$\mathrm{k}_{\mathrm{GTX} 3}$ & 0.333 & 0.387 & \\
$\mathrm{k}_{\mathrm{dcGTX} 2}$ & 0.203 & 0 & \\
$\mathrm{k}_{\mathrm{dcGTX} 3}$ & 0.326 & $9.2410^{4}$ & $9.2710^{4}$ \\
sse & $10.1610^{*}$ & 36.34 & 34.93 \\
$\mathrm{rmse}$ & 42.07 & &
\end{tabular}


2 Table 4: Comparison of root mean square error between the different models

3

\begin{tabular}{ccccc}
\hline Model & DG3+OT1 & 2C & 1C1 & $\begin{array}{c}\text { 1C2 } \\
\mathrm{k}=\mathrm{f}(\mathrm{GTX} 3 \mathrm{i}, \mathrm{GTX} 2 \mathrm{i})\end{array}$ \\
\hline sse & 8471 & 8717 & 13320 & 7327 \\
\hline rmse & $\begin{array}{c}\text { Not } \\
\text { defined }\end{array}$ & 31.13 & 32.01 & 24.71 \\
\hline
\end{tabular}

4

5 


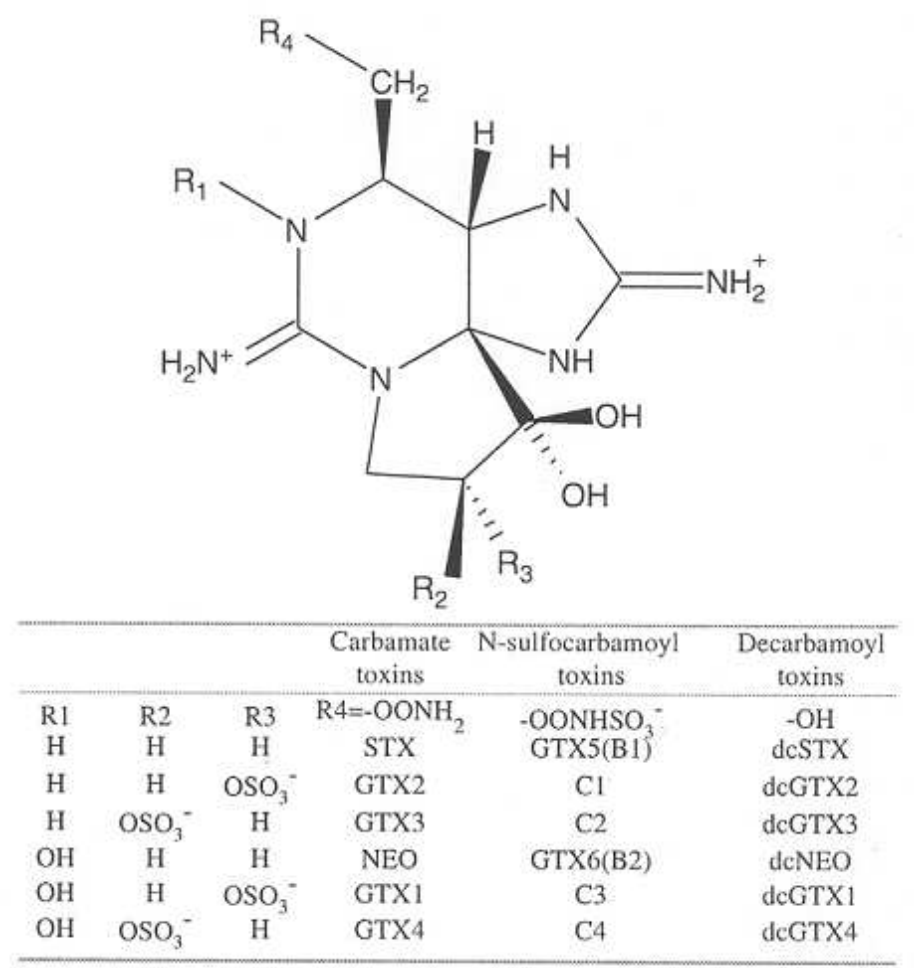

28 Figure 1: Chemical structure of paralytic toxins. Only the 16 compounds more frequently 29 found in the phytoplankton and molluscs are represented (Oshima, 1995).

30 
STX

C1

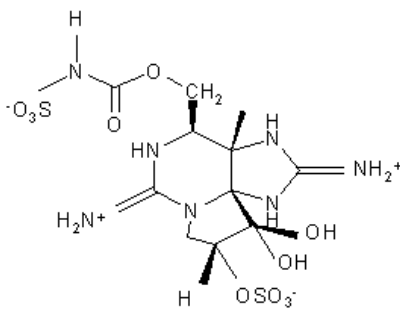

Hydrolyse
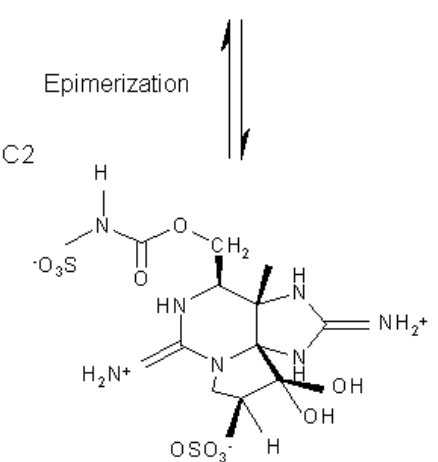

GTX1

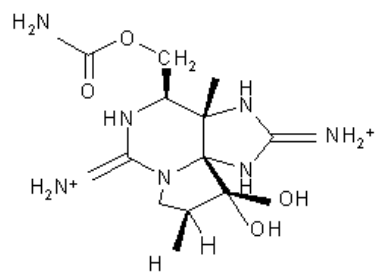

Reduction

$\mathrm{H}_{2} \mathrm{~N}$

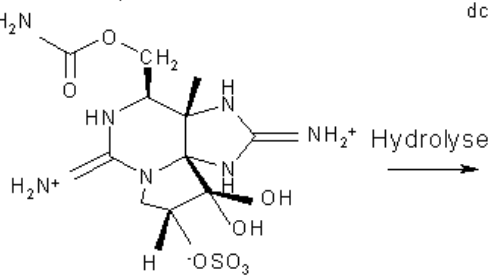

dc GTX2

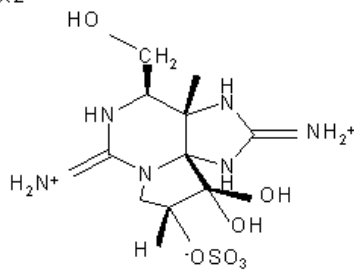

Reduction

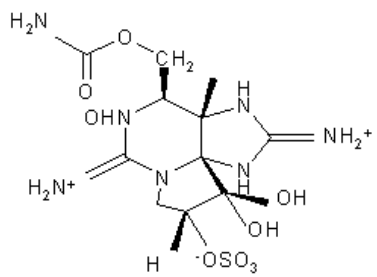

32 Figure 2: Examples of possible paralytic toxin biotransformations, as described by Oshima 33 (1995). 


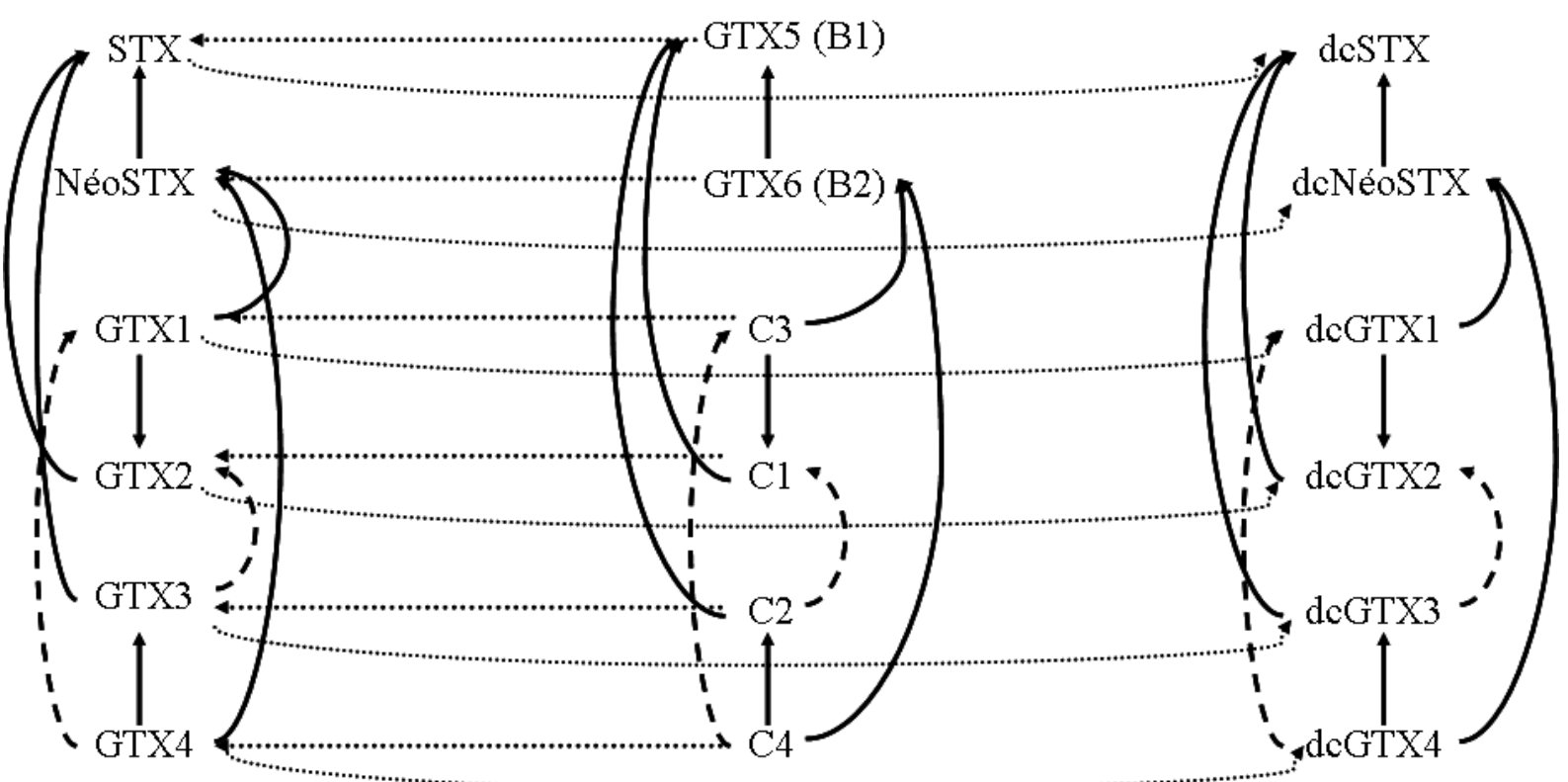

Figure 3: Synthetic diagram showing Oshima's biotransformation pathways applied to Paralytic Shellfish Toxins (solid arrow: reduction, dashed arrow: epimerisation, dotted arrow: hydrolysis) GTX: gonyautoxins, dc: decarbamoyls, STX: saxitoxin, C: toxin C. 


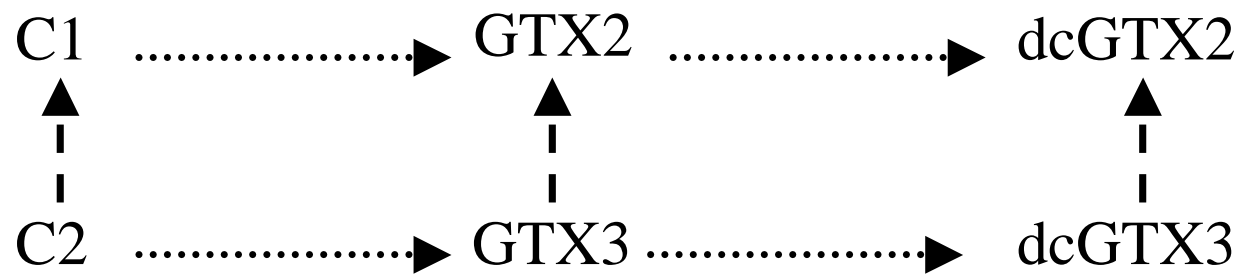

43 Figure 4: Simplified diagram showing biotransformations assumed to happen in Crassostrea 44 gigas when contaminated by Alexandrium minutum (dashed arrows: epimerisation, dotted 45 arrows: hydrolysis).

46

47

48 


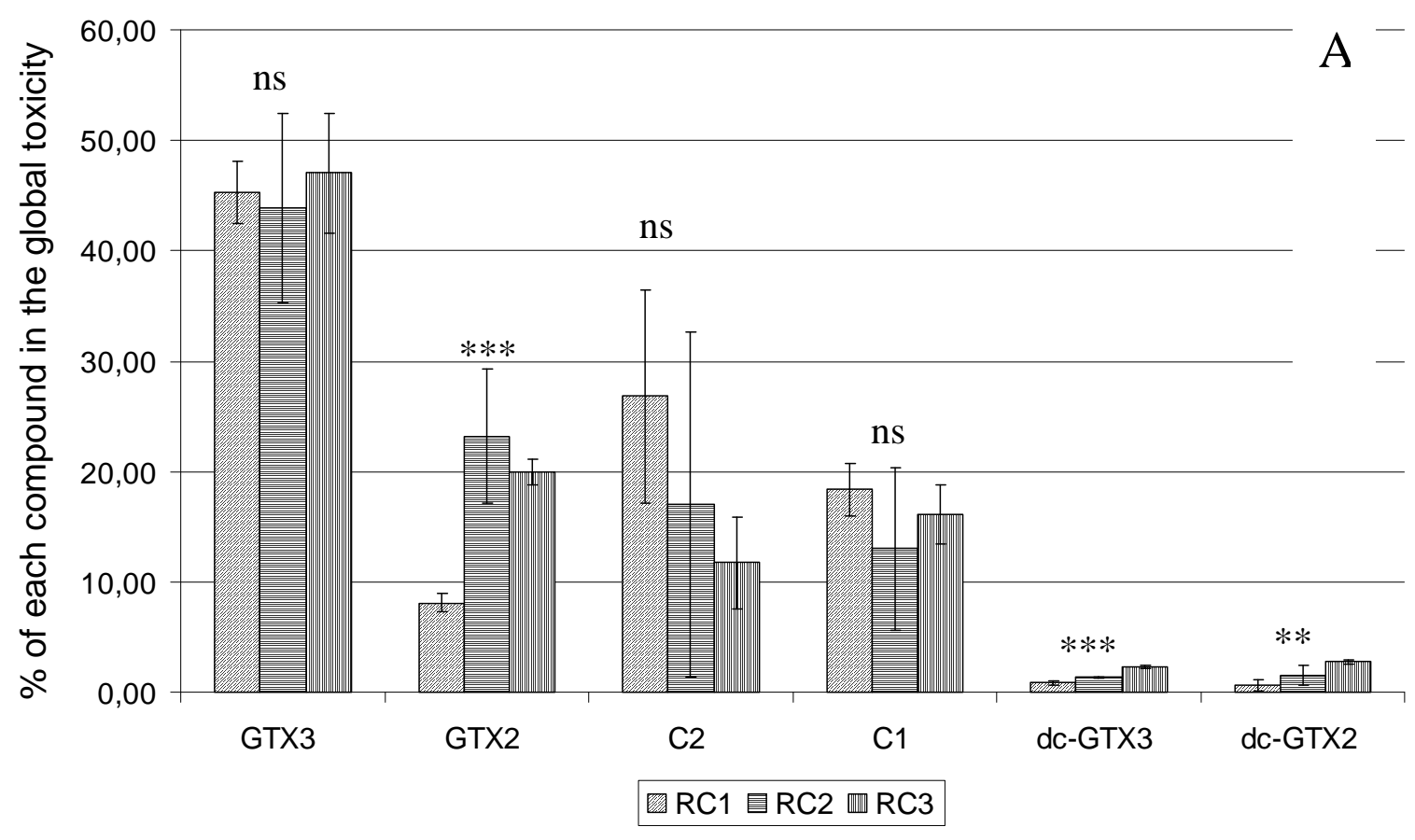

49

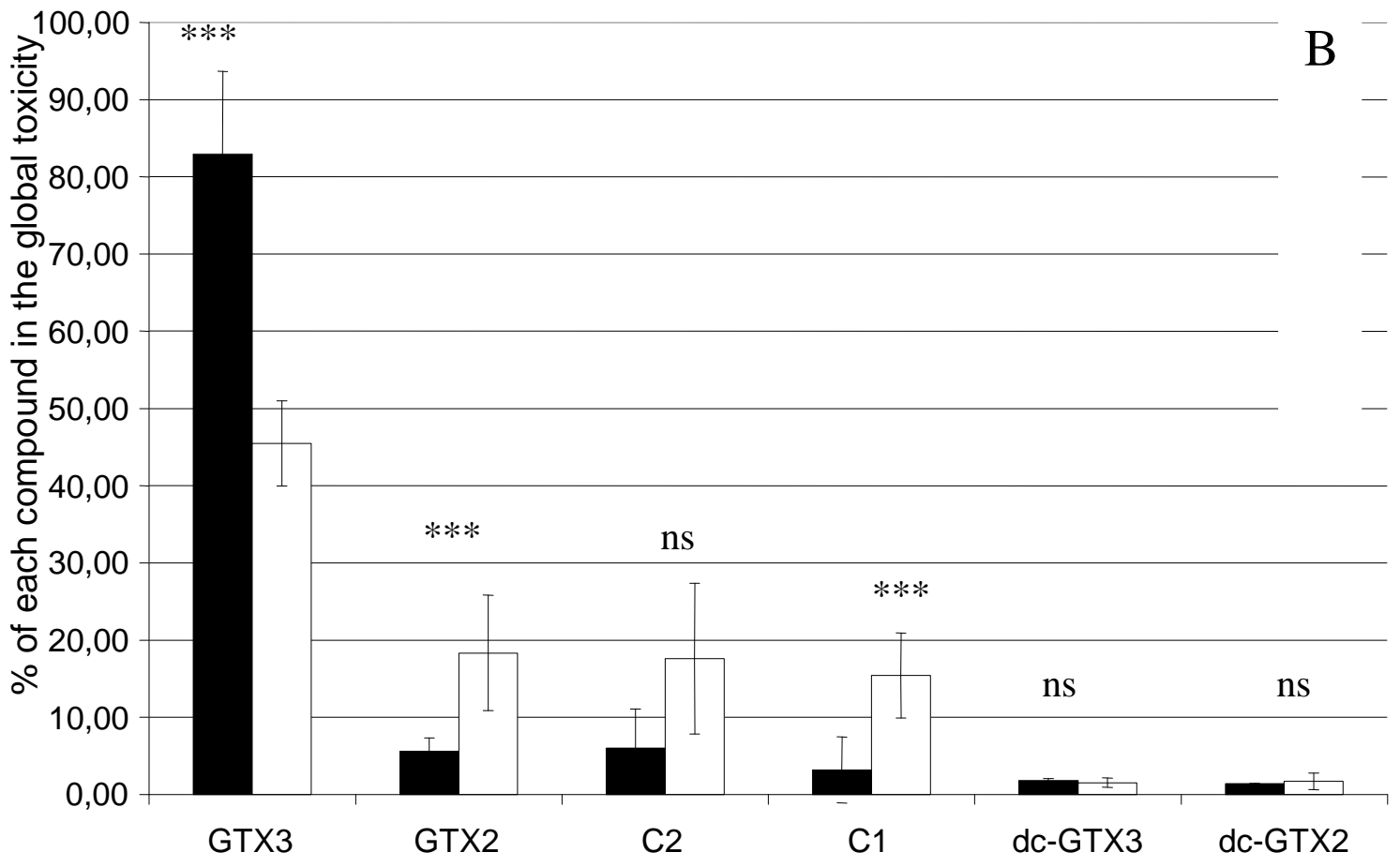

52 Figure 5: A: Toxin profiles in percentage of oysters in raceway 1, 2 and 3. B: Mean oyster

53 (black bars) and A. minutum (white bars) toxin profiles. ANOVA1 test (Matlab 6.5). GTX:

54 gonyautoxins, C: C toxins and dc: decarbamoyls; ns: no significant result. 


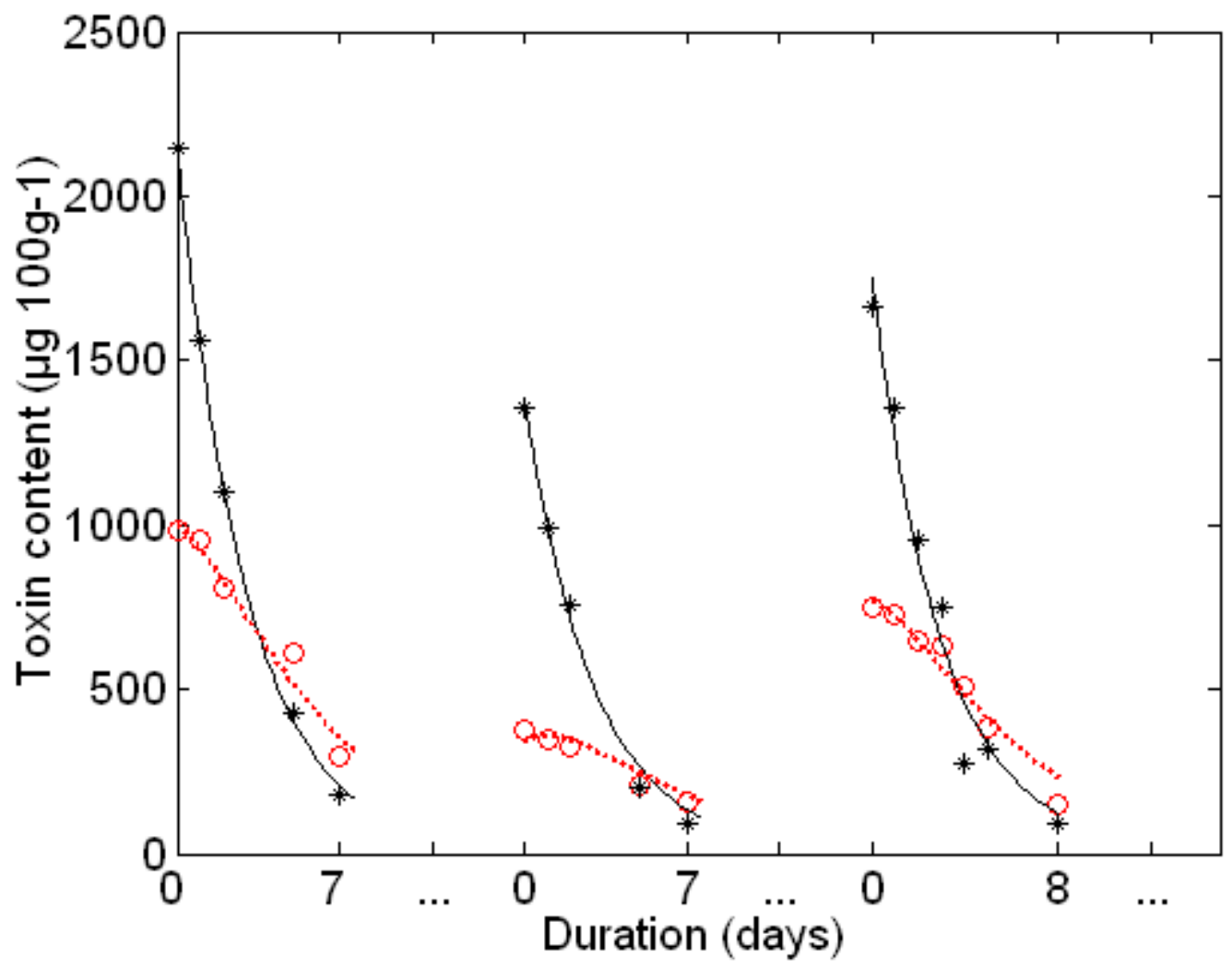

58

59 Figure 6: GTX3 (solid lines) and GTX2 (dotted lines) detoxification kinetics in digestive 60 gland, according to the DG3 model 


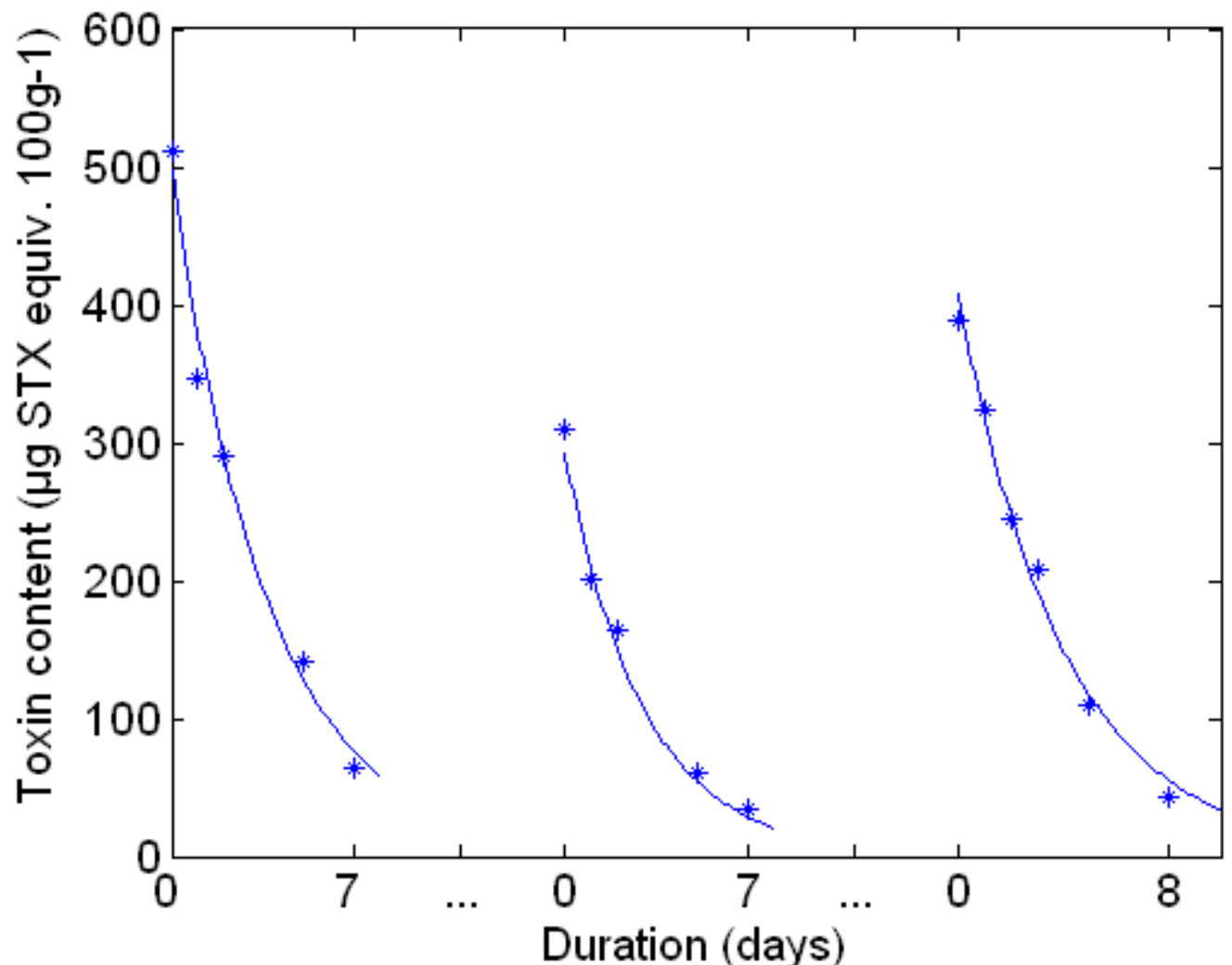

62

63 Figure 7: Detoxification kinetics in total flesh using the one-compartment model with the 64 detoxification rate depending only on initial concentration of GTX2 and GTX3 (1C2). 65 66 